Proceedings of the 33rd Annual Scientific Meeting of the European Embryo Transfer Association (AETE); Bath, United Kingdom, September 8th and 9th, 2017.

\title{
Effects of nutrition on sexual development of bulls
}

\author{
Heinrich Bollwein ${ }^{1}$, Fredi Janett, Martin Kaske \\ Clinic of Reproductive Medicine, Vetsuisse-Faculty, University of Zurich, CH-8057 Zurich, Switzerland.
}

\begin{abstract}
In the last decades a series of attempts have been made to improve reproductive performance of bulls via optimizing nutrition. Although an increase in energy uptake during the post-weaning period of calves led to a faster growing rate, it had no positive effects on sexual development. In contrast, a high-nutrition diet during the prepubertal period reduced the age at puberty of the bulls and increased the size/weight of the testis and the epididymal sperm reserves. This faster sexual development was associated with an increased transient LH peak, which seemed to be mediated by an increase in serum IGF-I concentrations. However, the exact mechanisms responsible for the interaction between nutrition and the subsequent development of calves are still not clear. Sexual development of bull calves depends not only on nutrition of the calves after birth but also on the feed intake of their mothers during pregnancy. A high-nutrition diet fed to the mother during the first trimester has negative effects on the reproductive performance of their offspring. In summary, growth, health and reproductive performance can be improved by nutrition, but further studies are necessary to obtain a better understanding about the mechanisms responsible for this phenomenon.
\end{abstract}

Keywords: nutrition, puberty, reproductive performance.

\section{Introduction}

Because of the introduction of genomic selection in cattle breeding a few years ago, the relevance of the reproductive performance of bulls has increased tremendously. Using this new method, the breeders are able to obtain information about the genetic value of the bulls at either the embryonic period or immediately after birth. With this information, they may be able to obtain semen from bulls with high genetic value earlier. One factor that limits this goal of the breeders is the high variability in the onset of puberty and sexual maturation in bull calves (Brito et al., 2012).

It is well known that there is a relationship between body weight and sexual development (Brito et al., 2012). Therefore, a series of attempts have been made to improve the growth of bull calves. However, contradictory results have been obtained via the supplementation of feed. There are even reports that a high-energy feed intake during the pubertal period has negative effects on the health and reproductive performance of bulls (Coulter and Kozub, 1984; Coulter et al., 1987). In addition, there is now evidence that the nutritional differences in feed during the prepubertal period (Brito et al., 2007a, c, d) or even the feed intake of the mothers (Sullivan et al., 2010, Jaquiery et al., 2012) can affect the development of the calves during later stages of life. The aim of this paper is to give a review of the literature dealing with the effects of nutrition on sexual development of bull calves.

\section{Physiology of sexual maturation in bulls}

For a better understanding of the effects of nutrition on sexual development it is important to be familiar with the physiological alterations occurring during this time period in bulls. An excellent overview of this topic has been given from Rawlings et al. (Rawlings et al., 2008). Therefore, only some aspects of the alterations occurring during sexual development in bulls will be described in this paper.

Testicular growth follows a sigmoidal pattern in bull calves, with small changes occurring up to 25 weeks of age, followed by a distinct increase in changes until puberty, and a slowing down of growth as the bull reaches sexual maturation (Abdel-Rauf, 1960; Macmillan and Hafs, 1968; Amann, 1983). In bulls, puberty is commonly defined as the time when the scrotal circumference (SC) is at least $28 \mathrm{~cm}$ and the ejaculate has a concentration of at least 50 million sperm $/ \mathrm{ml}$ with $\geq 10 \%$ progressively motile sperm, and sexual maturation is defined as the first time when the ejaculate consists of $\geq 70 \%$ morphologically normal sperm (Wolf et al., 1965).

Based on the gonadotropin and testosterone concentrations in blood plasma, the reproductive development of bulls can be divided into three periods: the infantile, prepubertal and pubertal periods. During the infantile period, which lasts from birth to up to 8 weeks of age, there are low concentrations of both gonadotropins and testosterone (Amann et al., 1986; Rawlings et al., 2008). In the following prepubertal period, ranging from 8 to 20 weeks of age, a transient increase in gonadotropin concentration and a concurrent small increase in testosterone secretion occur (Amann and Walker, 1983; Barth et al., 2008; Rawlings et al., 2008). The concentration of LH starts to increase at 4 to 5 weeks and is at a maximum concentration from 12 to 16 weeks of age. It then falls, reaching a baseline at 25 weeks of age (Amann and Walker, 1983; Barth et al., 2008). The early postnatal increase in LH secretion is clearly triggered by an increase in the frequency of pulses of GnRH secretion (Rodriguez and Wise, 1989). High LH concentrations during the prepubertal period have a positive effect on sexual development (Secchiari et al., 1976). Calves with a higher LH secretion at this time period reach puberty earlier than calves with lower 
LH concentrations during the prepubertal period (Amann and Walker, 1983; Evans et al., 1995). Blood FSH concentrations are generally also elevated during the prepubertal period, but changes in FSH are less pronounced than the corresponding changes in LH. Calves that achieve a greater FSH concentration during calfhood are expected to develop larger testes and possibly reach puberty at an earlier age. The age at which SC first reaches $28 \mathrm{~cm}$ has been shown to occur earlier in FSH-treated calves than in saline-treated (control) calves. The concentration of FSH decreases to baseline levels by approximately 25 weeks of age (Miyamoto et al., 1989; Evans et. al., 1996; Bagu et al., 2006). Serum concentrations of testosterone increase slowly from birth to approximately 20 weeks of age; subsequently, testosterone concentrations increase rapidly until 35 weeks of age (Secchiari et al., 1976; Lacroix et al., 1977; Sundby and Velle, 1980; Miyamoto et al., 1989; Rawlings and Evans, 1995; Evans et. al., 1996). The subsequent distinct increase in testosterone concentrations after 20 weeks of age occurs during the period of rapid growth of the testes, but interestingly, it also occurs during a time period with low gonadotropin secretion (Bagu et al., 2006). The period of the most active spermatogenesis in bulls is at the end of the early postnatal increase in LH secretion and is at the time when FSH declines from its maximum concentration during the prepubertal period (Rawlings et al., 2008).

It has been hypothesized by Brito et al. (2007b) that endogenous metabolic hormones such as leptin, insulin, GH and IGF-I, which have distinctly altered concentrations during the pubertal period, could have distinct effects on the sexual development of bulls. The authors have shown characteristic alterations of the serum concentrations of leptin, insulin, GH, IGF-I and testosterone and moderate correlations of these hormones with body weight, backfat, SC and paired testes volume. Leptin, insulin, GH and IGF-I concentrations together accounted for $63 \%$ of the variation in SC and $59 \%$ of the variation in paired testes volume. Therefore, Brito et al. (2007b) assumed that these hormones might also be involved in testicular development during the pubertal phase.

\section{Effects of modifications in nutrition starting during the pubertal period}

Most studies dealing with the effect of nutrition on sexual development have been performed after the weaning of beef bulls (Pruitt et al., 1986; Coulter et al., 1987; Mwansa and Makarechia, 1991; Ohl et al., 1996; Brito et al., 2012). As bulls are usually weaned at an age of approximately 7 to 8 months (Brito et al., 2012), this means that the modification of nutrition was started during the pubertal period after the transient increase in gonadotropin concentration. Most often a positive effect of feeding a high-nutrition diet during the pubertal period on SC and testis weight at 12 to 15 months of age but no effect or even negative effects on sperm production and semen quality was reported (Wolf et al., 1965; Secchiari et al., 1976; Amann et al., 1986). These deleterious effects of an excessive average daily gain (ADG) during the post-weaning period are likely due to fat deposition around the testicular vascular cones and the testes, thus, causing heat stress during spermatogenesis (Coulter et al., 1997). Furthermore, there is some evidence that excessive energy intake in young bulls may cause laminitis (Greenough et al., 1990), as well as abnormal bone and cartilage growth, resulting in stiffness and lameness. In a recent study, where beef bulls were fed diets with a low-, medium- or high-nutritional content from 6 to 16 months of age (Brito et al., 2012), no associations between ADG and the sexual development of the bulls could be detected. These observations are consistent with the hypothesis that the effects of a high-nutrition diet after the early increase in gonadotropin are negligible (Brito et al., 2007d; Rawlings et al., 2008).

\section{Effects of modifications in nutrition starting during the prepubertal period}

Also Brito et al. (2007a, c, d) were among the first authors to investigate the effects of modifications to their nutrition on bull calves before weaning on their later reproductive performance. In several trials (Brito et al., 2007a, c, d) they clearly demonstrated that a high nutrition during the prepubertal period resulted in a more sustained increase in LH pulse frequency and bigger testicles at maturity. Therefore, LH secretion during the prepubertal period may prime testicular development and determine maximum adult testicular size (Barth et al., 2008). Circulating IGF-I concentrations increased constantly during the prepubertal and pubertal periods, indicating that IGF-I may be involved in regulating sexual development. The temporal association between $\mathrm{GnRH} / \mathrm{LH}$ secretion and IGF-I concentration is a strong indicator for a regulatory role of IGF-I on GnRH secretion, but more studies should be conducted to determine whether IGF-I can indeed promote $\mathrm{GnRH}$ secretion in bulls (Barth et al., 2008). Nutrition also affected testosterone concentrations, which suggests effects on Leydig cell number, their function, or both. A consistent observation was that leptin, insulin, and GH concentrations did not differ among the groups with different nutrition levels during the period of the early gonadotropin increase and therefore were not involved in the differences in LH secretion. Therefore, the role of these hormones, if any, in regulating GnRH secretion is permissive. However, leptin and insulin had moderate to good correlations with SC and paired testes volume in some of the experiments, indicating that these hormones may promote testicular development (Barth et al., 2008).

\section{Effects of modifications in nutrition starting during the infantile period}

There is very little information regarding the effects of a modification of nutrition starting during the infantile period. In one study (Bratton et al., 1956) carried out more than 60 years ago, restriction of feed intake in Holstein bull calves from 1 to 80 weeks of age had a tremendous negative effect on pubertal development. In recently published studies, Dance et al. $(2015,2016)$ examined the effects of early life nutrition on reproductive development in Holstein 
bulls. Twenty-six Holstein bull calves were randomly allocated into 3 groups at approximately 1 week of age to receive either a low-, medium-, or high-nutrition diet from 2 to 31 weeks of age. Afterwards, all animals were fed the medium-nutrition diet. While there were no effects of nutrition on basal FSH concentrations, the increase in LH during the prepubertal period was advanced by 8 weeks (11 vs. 19 weeks) and mean LH concentrations were higher in bulls fed the high-nutrition diet than in those of the other 2 groups. Furthermore, bulls fed the high-nutrition diet had greater testosterone concentrations than those fed the low-nutrition diet from 11 to 27 weeks. Bulls fed the high-nutrition diet were younger at puberty and when they reached a SC of $28 \mathrm{~cm}$ than bulls fed the low-nutrition diet. In a similar study performed recently on Holstein-Friesian and Jersey bull calves between 3 to 49 weeks of age these results could be confirmed (Byrne et al., 2017). In addition, Dance et al. (2015) noticed at 72 weeks, that bulls fed the highnutrition diet had greater paired testes weights. The estimated number of sperm produced by day in the bulls of the high-nutrition group was about $9 \%$ higher compared to the bulls of medium-nutrition group and about $30 \%$ higher than the number estimated in bulls of the low-nutrition group, while no differences in sperm quality were noticed depending on nutrition of the bulls (Dance et al., 2016). Overall, the results obtained by Dance et al. $(2015,2016)$ and Byrne et al. (2017) are consistent with the studies from Brito et al. (2007a, c, d), who modified the nutrition of beef bulls starting at the prepubertal period. All these studies provide clear evidence that nutritional modulation of bull calves before puberty has profound effects on reproductive development. Because Dance et al. (2015) and Byrne et al. (2017) modulated the nutrition during the infantile and prepubertal periods, it is unclear, however, whether a nutritional modulation is required for both periods to obtain these effects on reproductive development or whether a shorter time interval would be as effective.

\section{Effects of modifications in nutrition limited to the infantile period}

We conducted two own studies to characterize the effects of an ad libitum (AdL) feeding of milk within the first three weeks of life compared to the effects of an established restrictive feeding protocol on performance, health status, metabolism and the onset of reproductive activity in bull calves

In the first experiment (Maccari et al., 2015; Prokop et al., 2015), 48 Holstein bull calves were randomly assigned to a group fed milk AdL for three weeks or to a group of restrictively fed calves. Calves were transferred from calf hutches into a group pen at either the second or third weeks of life. After the third week, the housing, feeding and management of calves from both groups were identical. Restricted amounts of milk replacer were offered, as well as a total mixed ration, concentrates and hay, and water was available AdL. The volume of milk replacer offered was reduced constantly from week 5 to 10 of life. Subsequent fattening was based on an established concentrate-based ration until slaughter at an age of eight mo. Average daily gains differed markedly: restrictively fed calves achieved an average gain of $380 \mathrm{~g}$ per $\mathrm{d}$ within the first three weeks of life, and the ADG of the AdL calves was threefold higher $(1,280 \mathrm{~g})$. As a result of the different feeding protocols within the first three weeks of life, some AdL-fed calves achieved a weight well above $80 \mathrm{~kg}$ by the fourth weeks, whereas most restrictively fed calves did not reach a body weight of $60 \mathrm{~kg}$ during this period. On average, AdL-fed calves were $20 \mathrm{~kg}$ heavier than the restrictively fed calves at an age of 22 days.

Calves fed restrictively in their first three weeks of life had lower testosterone plasma concentrations at an age of 10 weeks than AdL-fed calves, i.e. sexual development was accelerated by an intensified feeding within the first three weeks of life.

The effect of nutritional programming was obvious only at the time of slaughter in those calves that did not suffer from severe bronchopneumonia at some point. Calves with a history of pneumonia grew significantly less than healthy calves, and the effects of a higher level of nutrition were totally abolished.

We recently performed another study (Bollwein H; 2017; Vetsuisse-Faculty, University of Zurich, Zurich, Switzerland; unpublished results) for which the results are not yet complete but that would be useful to include here for the discussion of this issue. The objective of this study was to investigate whether a short-term postnatal nutritional trigger of 4 weeks affects daily weight gain, health status and the onset of puberty in Brown Swiss calves. Twenty-four bull calves were fed milk either restrictively (RES) or AdL for four weeks. Housing was identical throughout this initial feeding period and also thereafter, when calves were transferred to group pens. Feeding was similar for all calves from week 5 of life and beyond when a conventional ration for the fattening of bulls was offered. The reproductive performance of the calves was assessed by frequent measurements of SC. As soon as it reached $26 \mathrm{~cm}$, electroejaculations were performed biweekly to determine the quantity and quality of the semen. There were clear differences in the results with respect to milk ingestion. The high inter-individual variance in the group of AdL-fed calves indicated that roughly one third of those calves did not consume more milk than calves fed according to the established restrictive feeding protocols while other AdL-fed calves ingested $12 \mathrm{~L}$ per $\mathrm{d}$ or more. Thus, we subdivided the group of AdL-fed calves into a group of calves with a substandard milk intake (designated as AdL-low) and calves with a greater-than-normal level of milk consumption (designated as AdL-high). In fact, AdLhigh calves consumed roughly twice as much milk as the RES calves and calves in the AdL-low group, both in the first two weeks of life and in the subsequent two weeks under the different feeding protocols. In agreement with milk intake, daily weight gains were not markedly different between RES calves and AdL-low calves (Fig. 1). However, AdL-high calves achieved a ADG of $600 \mathrm{~g}$ by the first two weeks of life and gained almost $1,200 \mathrm{~g}$ /day in the subsequent two weeks. When we followed these bull calves until the end of the study, 
AdL-high calves remained 30-40 $\mathrm{kg}$ heavier during the entire period than RES calves and AdL-low calves (Fig. 1). These results demonstrate the impact of energy intake in early calfhood on subsequent development.

With respect to reproductive performance, the onset of puberty based on the analysis of ejaculates did not differ between the groups (278vs. $274 v s .275$ days) despite the considerable variance within each group. An SC of $28 \mathrm{~cm}$ was reached somewhat earlier (Fig. 1) in AdL-high calves (252 days) than in the AdL-low (271 days) and the RES calves (268 days). Testosterone plasma concentrations assessed between 6 and 13 months of age were significantly higher in AdL-high calves than in calves fed restrictively for the first four weeks of life. A significant difference also occurred in the proportion of morphologically normal sperm, which was higher in AdL-fed calves than in RES-fed calves between 10 and 16 months of age. In conclusion, there was a trend in the data suggesting that a high level of nutrition limited to the infantile period may also affect long-term reproductive

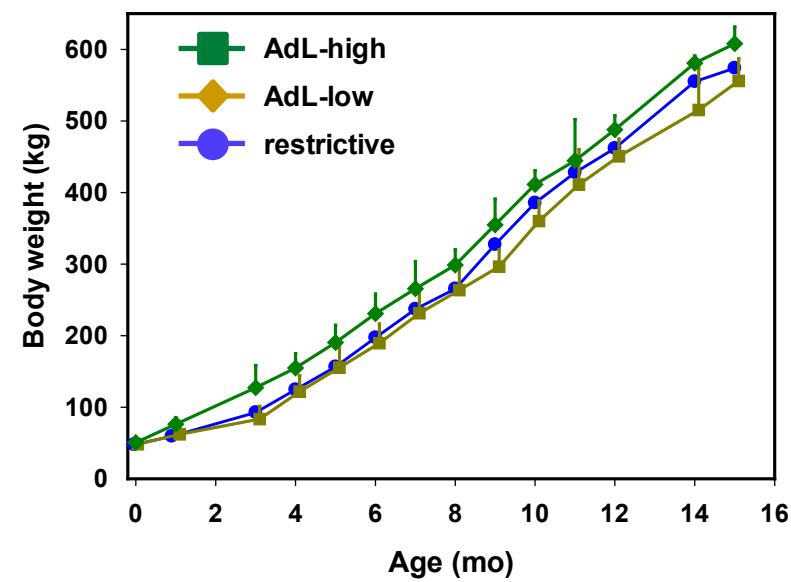

performance but significant differences were rare. This might be due to the enormous inter-individual differences within each group. These differences also demonstrate that the onset of puberty is determined by a variety of factors and the intensity of pre-weaning milk feeding is only one of these factors. In addition, the number of animals analyzed in this study could simply be too small to demonstrate an effect of pre-weaning feeding intensity on the subsequent sexual performance of bull calves. Alternatively, the period of intensive milk feeding might have been too short to provoke more profound and long-lasting consequences. In that context, it should be taken into consideration that ADG was reduced markedly in all calves after transfer from individual hutches to a group pen. This setback may be harmful because it still falls in the critical period when the regulatory systems of the calves are responsive to epigenetic factors, and therefore, positive effects of events occurring during the first week of life may be abolished. Whether this speculation is valid should be investigated in forthcoming studies.

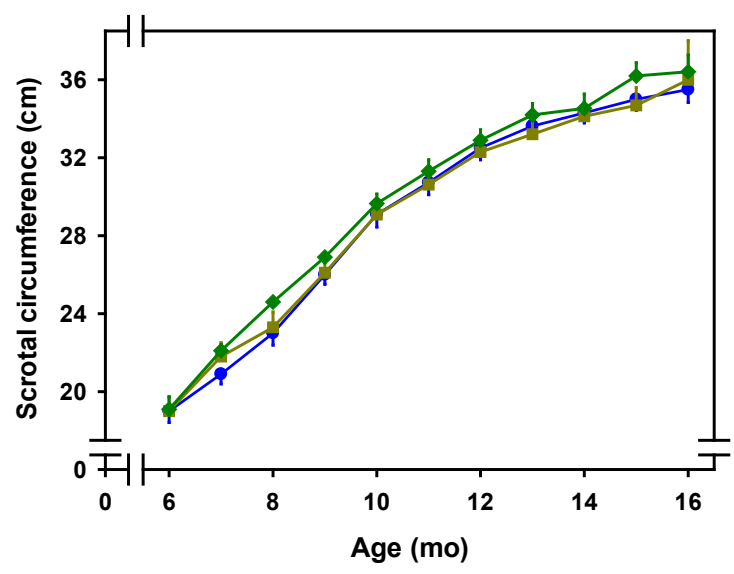

Figure 1. Differences in milk feeding intensity during the first four weeks of life induces long-lasting differences in weight gain and scrotal development in Brown Swiss calves. From Bollwein et al. (2016).

\section{Effects of modifications in nutrition during the fetal period}

The hypothesis that in male calves the development of the testis and the hypothalamicpituitary axis along with the associated synthesis of gonadotropins would be affected by maternal dietary intake and genotype and would correlate with IGF-I and leptin levels was proven by Sullivan et al. (2010). For this purpose, pregnant heifers were divided into two treatment groups stratified by body weight and genotype. For the first trimester of gestation, the groups were fed either high $(\mathrm{H})$ or low (L) protein and energy diets. During the second trimester, half of the animals in each treatment group were switched to the alternate treatment group. This resulted in four treatment groups: high/high $(\mathrm{HH})$, high/low (HL), low/high (LowH), low/low (LL). During the third trimester all heifers were fed a standard diet. Paired testicular weight was positively associated with the LowH nutritional group. There was a tendency for bull calves in the HL group to have smaller paired testicle volumes than those in the LowH group. Bull calves in the LL group had higher FSH than those in the
HL group. There was a tendency for HL bull calves to have higher LH concentrations than LowH bull calves. Serum testosterone concentrations were not associated with nutritional group. Reduced circulating concentrations of FSH and lower paired testicular weights in prepubertal bull calves whose dams received higher dietary levels of protein and energy during early gestation suggest that the reproductive axis of beef bulls may be susceptible to nutritional perturbations in utero (Sullivan et al., 2010). According to their results, the authors of this study concluded that a compromised development of the hypothalamic-pituitary-gonadal axis in the early fetal stage may result in a reduced prepubertal gonadotrophin surge in male calves. Overall, the findings of this study suggest a deleterious effect of elevated dam dietary protein and energy in the first trimester of gestation on the reproductive development of their bull calves.

\section{Effects of modifications of nutrition during the periconceptional period}

To the best of our knowledge up to know there have been no studies on the effect of nutrition around 
the time of conception in cattle on the reproductive performance of their offspring. However, such investigations have been performed in sheep. Growth and body composition from birth to adulthood was measured in male and female singleton offspring of ewes that were undernourished before, before and after, or only after conception, and they measured carcass and organ weights after slaughter (Jaquiery et al., 2012). Fiveyear-old Romney ewes were randomly allocated to a control group or to one of three groups that were undernourished around the time of conception. Normally nourished controls $(\mathrm{N})$ were fed a maintenance ration. The diets of the ewes in the three undernourished groups were adjusted to achieve and maintain a weight loss of $10-15 \%$ body weight from 61 days before mating to the time of mating (day 0; UN-61-0), from 61 days before to 30 days after mating (UN-61-30), or from 2 days before to 30 days after mating (UN-2-30). Thereafter, all animals were fed in the same way as the control group. Total gonadal weight was affected by periconceptional undernutrition in animals of both sexes but in opposite ways. UN males had heavier testes and $\mathrm{UN}$ females had lighter ovaries than $\mathrm{N}$ animals. As all time periods of undernutrition were associated with a similar effect on male body composition, it was assumed that the results were via a direct effect on the blastocyst or early embryo, and not on the ovum prior to conception, or via an indirect effect mediated by the altered adaptations to pregnancy observed in UN-61-0 and UN-61-30 groups. The authors of this study also mentioned that future investigations are necessary to obtain a better understanding of the signals in embryonic life that determine sex-related growth differences. However, it would be interesting if these effects were also observed in cattle.

\section{Conclusions}

Sexual development of bull calves can be influenced by a modulation of nutrition during their infantile and prepubertal periods. However, the frequent practice of feed supplementation during the pubertal period after weaning does not seem to have positive effects on sexual development (Fig. 2). Interestingly, the development of bull calves is affected by their nutrition not only after but also before birth. In contrast to the positive effects of high feed intake by the bull calves during the first week after birth, a high-nutrition diet fed to the mother during the first trimester seems to have negative effects on the development and the reproductive performance of their offspring later in life. It has not yet been determined whether there is also an effect of periconceptional feed intake by the cows on the development of their male offspring, as has been reported in sheep. Several studies have demonstrated that modifications in feed intake have an influence on the hypothalamic-pituitary-gonadal axis, which might be mediated by serum IGF-I concentrations, but the exact mechanisms responsible for the interaction between nutrition and the subsequent development of offspring are not yet clear. Therefore, further studies are necessary to obtain a better understanding of the phenomenon of effects of nutrition on sexual development in bulls to be able to optimize the performance of young bulls.

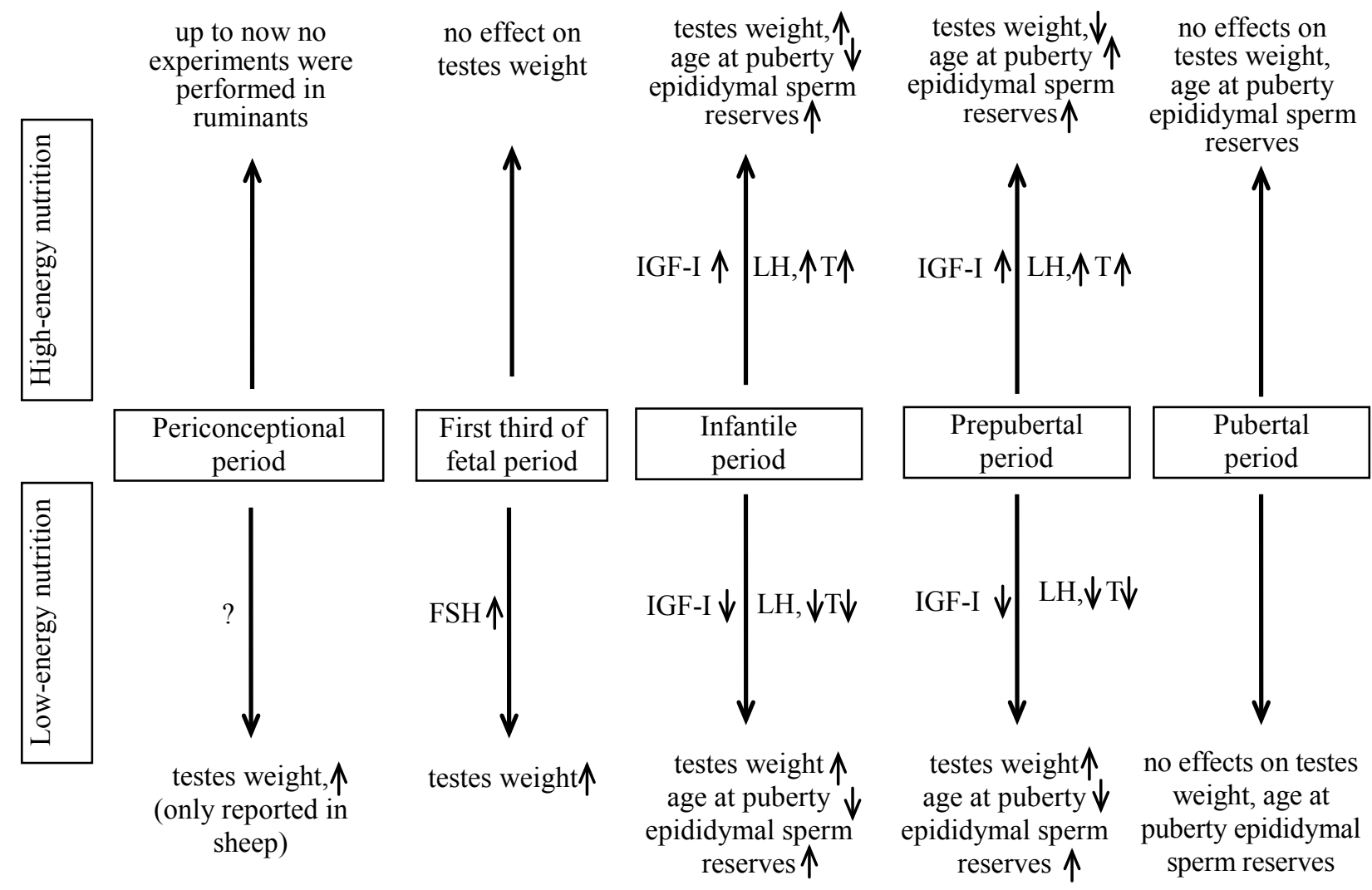

Figure 2. Scheme summarizing the nutritional effects through the different developmental stages $(\mathrm{T}=$ testosterone). From Bollwein et al. (2016). 


\section{Acknowledgments}

We thank Swissgenetics and the Förderverein Bioökoomieforschung for their financial support of our studies.

\section{References}

Abdel-Raouf M. 1960. The postnatal development of the reproductive organs in bulls with special reference to puberty (including growth of the hypophysis and the adrenals). Acta Endocrinol, 34(suppl. 49):1-109.

Amann RP. 1983. Endocrine changes associated with onset of spermatogenesis in Holstein bulls. J Dairy Sci, 66:2606-2622.

Amann RP, Walker OA. 1983. Changes in the pituitary-gonadal axis associated with puberty in Holstein bulls. J Anim Sci, 57:433-442.

Amann RP, Wise ME, Glass JD, Nett TM. 1986. Prepubertal changes in the hypothalamic-pituitary axis of Holstein bulls. Biol Reprod, 34:71-80.

Bagu ET, Cook S, Gratton CL, Rawlings NC. 2006. Postnatal changes in testicular gonadotropin receptors, serum gonadotropin, and testosterone concentrations and functional development of the testes in bulls. Reproduction, 132:403-411.

Barth AD, Brito LF, Kastelic JP. 2008. The effect of nutrition on sexual development of bulls. Theriogenology, 70:485-494.

Bollwein H, Janett F, Kaske M. 2016. Impact of nutritional programming on the growth, health, and sexual development of bull calves. Domest Anim Endocrinol, 56(suppl):180-190

Bratton RW, Musgrave SD, Dunn HO, Foote RH, Henderson CR. 1956. Semen production and fertility of young bulls raised on three different energy levels of feed intake. J Anim Sci, 15:1296-1297 (abstract)

Brito LF, Barth AD, Rawlings NC, Wilde RE, Crews DH Jr, Boisclair YR, Ehrhardt RA, Kastelic JP. 2007a. Effect of feed restriction during calfhood on serum concentrations of metabolic hormones, gonadotropins, testosterone, and on sexual development in bulls. Reproduction, 134:171-181.

Brito LF, Barth AD, Rawlings NC, Wilde RE, Crews DH Jr, Mir PS, Kastelic JP. 2007b. Circulating metabolic hormones during the peripubertal period and their association with testicular development in bulls Reprod Domest Anim, 42:502-508.

Brito LF, Barth AD, Rawlings NC, Wilde RE, Crews DH Jr, Mir PS, Kastelic JP. 2007c. Effect of improved nutrition during calfhood on serum metabolic hormones, gonadotropins, and testosterone concentrations, and on testicular development in bulls. Domest Anim Endocrinol, 33:460-469.

Brito LF, Barth AD, Rawlings NC, Wilde RE, Crews DH Jr, Mir PS, Kastelic JP. 2007d. Effect of nutrition during calfhood and peripubertal period on serum metabolic hormones, gonadotropins and testosterone concentrations, and on sexual development in bulls. Domest Anim Endocrinol, 33:1-18

Brito LF, Barth AD, Wilde RE, Kastelic JP. 2012. Effect of growth rate from 6 to 16 months of age on sexual development and reproductive function in beef bulls. Theriogenology, 77:1398-1405.

Byrne CJ, Fair S, English AM, Urh C, Sauerwein H, Crowe MA, Lonergan P, Kenny DA. 2017. Effect of breed, plane of nutrition and age on growth, scrotal development, metabolite concentrations and on systemic gonadotropin and testosterone concentrations following a GnRH challenge in young dairy bulls. Theriogenology, 96:58-68.

Coulter GH, Kozub GC. 1984. Testicular development, epididymal sperm reserves and seminal quality in two-year-old Hereford and Angus bulls: effects of two levels of dietary energy. $J$ Anim Sci, 59:432-440.

Coulter GH, Carruthers TD, Amann RP, Kozub GC. 1987. Testicular development, daily sperm production and epididymal sperm reserves in 15-mo-old Angus and Hereford bulls: effects of bull strain plus dietary energy. J Anim Sci, 64:254-260.

Coulter GH, Cook RB, Kastelic JP. 1997. Effects of dietary energy on scrotal surface temperature, seminal quality, and sperm production in young beef bulls. $J$ Anim Sci, 75:1048-1052.

Dance A, Thundathil J, Wilde R, Blondin P, Kastelic J. 2015. Enhanced early-life nutrition promotes hormone production and reproductive development in Holstein bulls. J Dairy Sci, 98:987-998.

Dance A, Thundathil J, Blondin P, Kastelic J. 2016. Enhanced early-life nutrition of Holstein bulls increases sperm production potential without decreasing postpubertal semen quality. Theriogenology, 86:687-694

Evans AC, Davies FJ, Nasser LF, Bowman P, Rawlings NC. 1995. Differences in early patterns of gonadotrophin secretion between early and late maturing bulls, and changes in semen characteristics at puberty. Theriogenology, 43:569-578.

Evans AC, Pierson RA, Garcia A, McDougall LM, Hrudka F, Rawlings NC. 1996 Changes in circulating hormone concentrations, testes histology and testes ultrasonography during sexual maturation in beef bulls. Theriogenology, 46:345-357.

Greenough PR, Vermunt JJ, McKinnon JJ, Fathy FA, Berg PA, Cohen RD. 1990. Laminitis-like changes in the claws of feedlot cattle. Can Vet J, 31:202-208.

Jaquiery AL, Oliver MH, Honeyfield-Ross M, Harding JE, Bloomfield FH. 2012. Periconceptional undernutrition in sheep affects adult phenotype only in males. $J$ Nutr Metab, 2012:123610. doi: 10.1155/2012/123610.

Lacroix A, Garnier DH, Pelletier J. 1997. Temporal fluctuations of plasma LH and testosterone in charolais bull claves during the first year of live. Ann Biol Anim Biochim Biophys, 17:1013-1019.

Maccari P, Wiedemann S, Kunz HJ, Piechotta M, Sanftleben P, Kaske M. 2015. Effects of two different rearing protocols for Holstein bull calves in the first 3 weeks of life on health status, metabolism and subsequent performance. J Anim Physiol Anim Nutr, 99:737-746.

Macmillan KL, Hafs HD. 1968. Gonadal and extra gonadal sperm numbers during reproductive development of Holstein bulls. J Anim Sci, 27:697-700. 
Miyamoto A, Umezu M, Ishii S, Furasawa T, Masaki J, Hasegawa Y, Ohta M. 1989. Serum inhibin, FSH, $\mathrm{LH}$ and serum concentrations of $\mathrm{FSH}, \mathrm{LH}$ and testosterone levels and testicular inhibin content in beef bulls from birth to puberty. Anim Reprod Sci, 20:165178 .

Mwansa PB, Makarechian M. 1991. The effect of postweaning levels of diet energy on sex drive and semen quality of young beef bulls. Theriogenology, 35:1169-1178.

Ohl MW, Ott RS, Faulkner DB, Hornbuckle T, 2nd, Hess RA, Cmarik GF, Zinn GM. 1996. Effects of rate of gain on scrotal circumference and histopathologic features of the testes of half-sibling yearling beef bulls Am J Vet Res, 57:844-847.

Prokop L, Kaske M, Maccari P, Lucius R, Kunz HJ, Wiedemann S. 2015. Intensive rearing of male calves during the first three weeks of life has long-term effects on number of islets of langerhans and insulin stained area in the pancreas. J Anim Sci, 93:988-998.

Pruitt RJ, Corah LR, Stevenson JS, Kiracofe GH. 1986. Effect of energy intake after weaning on the sexual development of beef bulls. II. Age at first mating, age at puberty, testosterone and scrotal circumference. $J$ Anim Sci, 63:579-585.
Rawlings NC, Evans AC. 1995. Androgen negative feedback during the early rise in LH secretion in bull calves. J Endocrinol, 145:243-249.

Rawlings N, Evans AC, Chandolia RK, Bagu ET. 2008. Sexual maturation in the bull. Reprod Domest Anim,43(suppl. 2):295-301.

Rodriguez RE, Wise ME. 1989. Ontogeny of pulsatile secretion of gonadotropin-releasing hormone in the bull calf during infantile and pubertal development. Endocrinology, 124:248-256.

Secchiari P, Martorana F, Pellegrini S, Luisi M. 1976. Variation of plasma testosterone in developing Friesian bulls. J Anim Sci, 42:405-409.

Sullivan TM, Micke GC, Greer RM, Perry VE. 2010. Dietary manipulation of Bos indicus $\mathrm{x}$ heifers during gestation affects the prepubertal reproductive development of their bull calves. Anim Reprod Sci, 118:131-139.

Sundby A, Velle W. 1980. Plasma concentration of testosterone in young bulls in relation to age, rate of weight gain and stimulation with human chorionic gonadotrophin. $J$ Endocrinol, 86:465-469.

Wolf FR, Almquist JO, Hale EB. 1965 Prepuberal behavior and puberal characteristics of beef bulls on high nutrient allowance. J Anim Sci, 24:761-765. 